\title{
Through Alberta Eyes - the photographs of Orest Semchisen
}

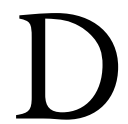
r. Orest Semchisen has always worked with great insight into life. During his first career, as a radiologist, he peered into bodies. He studied corporeal realities to reveal the body's resilience and strengths, but also to t find weaknesses.

While still working in medicine, Semchisen started documenting the vanishing landscapes and communities - rural and ethnic - in his native and beloved Alberta. He was born in Mundare, 8o kilometres east of Ed- monton, in 1932 to a family of Ukrainian heritage.

"Yes there is a presence here in $\mathrm{Al}$ berta," Semchisen has stated. "It is the presence of prairie and it permeates the architecture, the towns, the choice of colours. It is the vastness, the skies and the space. It is something that one does not see in the East or West Coast. It is subtle, palpable but here."

After retiring from radiology, Semchisen turned his highly resolved view completely to his photographic practice.
Through Alberta Eyes is comprised of five 20-piece sets of photographs. One of these sets, Remote Communities, is on display at Mount Saint Vincent Art Gallery, Halifax, NS, May 25 through July 30, 2006. The images in Through Alberta Eyes cover a sample of Semchisen's work from 1973 to 1986 . The full collection of his photos is housed at the National Archives of Canada, in Ottawa.

\section{Sean Flinn}

Freelance Writer

Halifax, NS

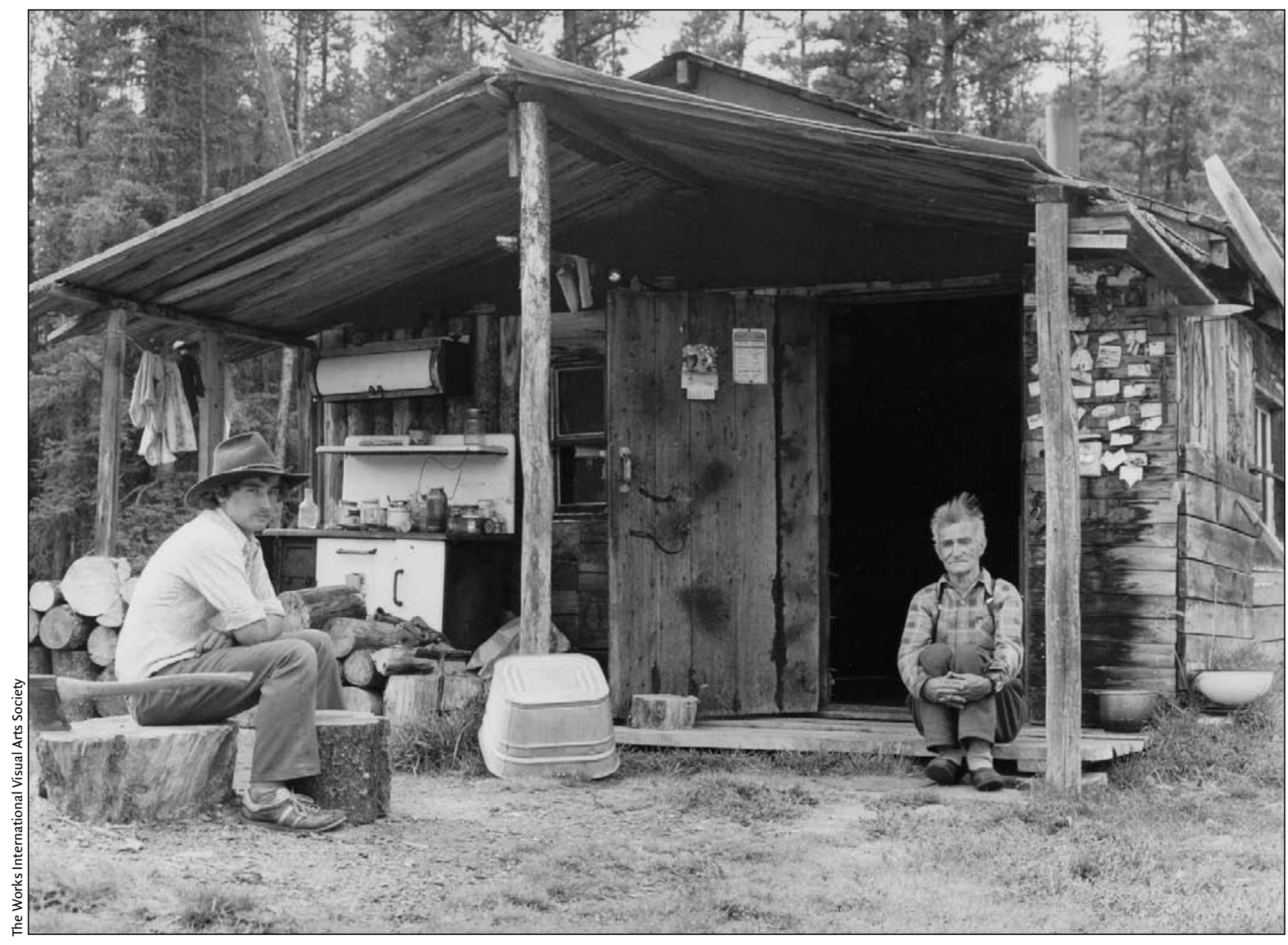

Through Alberta Eyes: In this photo, photographer Orest Semchisen leads viewers into the heart of a trapper's life, his cabin, out in the bush. The depth provided by the darkened doorway, the entrance to the tiny log and plank structure, pulls the viewer in to wonder what's inside at the core of this life.

Two modestly posed figures, the older and experienced trapper and his younger helper, or apprentice, stare out at you. They're surrounded by simple, utilitarian objects. The handle of an axe cut into a stump creates a line along the young man's thigh, the femur revealed.

Semchisen illuminates the interior of a life so we can see what's lost to us in the 21st century. 